Stud. Univ. Babeş-Bolyai Math. 64(2019), No. 3, 421-431

DOI: http://dx.doi.org/10.24193/subbmath.2019.3.12

\title{
Ball comparison for three optimal eight order methods under weak conditions
}

\author{
Ioannis K. Argyros and Santhosh George
}

\begin{abstract}
We considered three optimal eighth order method for solving nonlinear equations. In earlier studies Taylors expansions and hypotheses reaching up to the eighth derivative are used to prove the convergence of these methods. These hypotheses restrict the applicability of the methods. In our study we use hypotheses on the first derivative. Numerical examples illustrating the theoretical results are also presented in this study.
\end{abstract}

Mathematics Subject Classification (2010): 65D10, 65D99, 47J25, 47J05.

Keywords: Banach space, Fréchet derivative, efficiency index, ball convergence.

\section{Introduction}

In this paper we are concerned with the problem of approximating a solution $x^{*}$ of the equation

$$
F(x)=0,
$$

where $F: D \subseteq S \rightarrow T$ is a Fréchet-differentiable operator defined on a convex set $D$, where $S, T$ are subsets of $\mathbb{R}$ or $\mathbb{C}$.

Equation of the form (1.1) is used to study problems in Computational Sciences and other disciplines $[3,7,14,16,20]$. Newton-like iterative methods $[1,2,3,4,5,6,7$, $8,9,10,11,12,13,14,15,16,17,18,19,20,21,22,23]$ are famous for approximating a solution of the equation (1.1).

In this paper, we study the local convergence analysis of the methods defined for each $n=0,1,2, \cdots$ by Siyyam et al. [19]

$$
y_{n}=x_{n}-\frac{1}{F^{\prime}\left(x_{n}\right)} F\left(x_{n}\right),
$$




$$
\begin{aligned}
z_{n}= & x_{n}+(1+\beta) \frac{1}{F^{\prime}\left(x_{n}\right)}\left(F\left(x_{n}\right)+F\left(y_{n}\right)\right), \\
& -\frac{1}{F^{\prime}\left(x_{n}\right)} F\left(x_{n}\right)\left(F\left(x_{n}\right)-F\left(y_{n}\right)\right)^{-1} F\left(x_{n}\right) \\
& -\beta\left(\frac{1}{F^{\prime}\left(x_{n}\right)} F\left(x_{n}\right)+\left(F^{\prime}\left(x_{n}\right)+F^{2}\left(x_{n}\right) F^{\prime}\left(x_{n}\right)\right)^{-1} F\left(y_{n}\right)\right) \\
x_{n+1}= & z_{n}-A_{n}^{-1} F\left(z_{n}\right),
\end{aligned}
$$

where $x_{0} \in D$ is an initial point, $\beta \in S$,

$$
\begin{aligned}
A_{n} & =F^{\prime}\left(x_{n}\right)+\left(\left[x_{n}, y_{n}, z_{n} ; F\right]+\left[x_{n}, x_{n}, y_{n} ; F\right]\right)\left(z_{n}-x_{n}\right) \\
& +2\left(\left[x_{n}, y_{n}, z_{n} ; F\right]-\left[x_{n}, x_{n}, y_{n} ; F\right]\right)\left(z_{n}-y_{n}\right)
\end{aligned}
$$

and $[\cdot, \cdot, \cdot ; F]$ denotes a divided difference of order two for function $F$ on $D$. The second and third method are due to Wang et. al. [23] and are defined, respectively as

$$
\begin{aligned}
y_{n}= & x_{n}-\frac{1}{F^{\prime}\left(x_{n}\right)} F\left(x_{n}\right), \\
z_{n}= & x_{n}-\frac{1}{F^{\prime}\left(x_{n}\right)} F\left(x_{n}\right)\left(F\left(x_{n}\right)-2 F\left(y_{n}\right)\right)^{-1}\left(F\left(x_{n}\right)-F\left(y_{n}\right)\right), \\
x_{n+1}= & z_{n}-\frac{1}{F^{\prime}\left(x_{n}\right)} F\left(z_{n}\right) \\
& \times\left[\frac{1}{2}+\frac{1+\frac{8 F\left(y_{n}\right)}{5 F\left(x_{n}\right)}+\frac{2}{5}\left(\frac{F\left(y_{n}\right)}{F\left(x_{n}\right)}\right)^{2}}{1-\frac{12}{5} \frac{1}{F^{\prime}\left(x_{n}\right)} F\left(y_{n}\right)}\left(1+F^{\prime}\left(y_{n}\right)^{-1} F\left(z_{n}\right)\right)\right],
\end{aligned}
$$

and

$$
\begin{aligned}
y_{n}= & x_{n}-\frac{1}{F^{\prime}\left(x_{n}\right)} F\left(x_{n}\right), \\
z_{n}= & x_{n}-\frac{1}{F^{\prime}\left(x_{n}\right)} F\left(x_{n}\right)\left(F\left(x_{n}\right)-2 F\left(y_{n}\right)\right)^{-1}\left(F\left(x_{n}\right)-F\left(y_{n}\right)\right), \\
x_{n+1}= & z_{n}-F\left(x_{n}\right)^{-1} F\left(x_{n}\right)\left[\frac{1-\frac{2}{5} \frac{1}{F^{\prime}\left(x_{n}\right)} F\left(y_{n}\right)+\frac{1}{5}\left(F\left(x_{n}\right)^{-1} F\left(y_{n}\right)\right)^{2}}{1-\frac{12}{5} \frac{1}{F^{\prime}\left(x_{n}\right)} F\left(y_{n}\right)}\right. \\
& \left.+\left(1+4 \frac{1}{F^{\prime}\left(x_{n}\right)} F\left(y_{n}\right)\right) F^{\prime}\left(y_{n}\right)^{-1} F\left(z_{n}\right)\right] .
\end{aligned}
$$

Convergence ball of high convergence order methods is usually very small and in general decreases as the convergence order increases. The approach in this paper establishes the local convergence result under hypotheses only on the first derivative and give a larger convergence ball than the earlier studies, under weaker hypotheses. Notice that in earlier studies [19, 23] the convergence is shown under hypotheses on the eighth derivative. The same technique can be used to other methods. As a motivational example, define function $f$ on $D=\left[-\frac{1}{2}, \frac{3}{2}\right)$ by

$$
f(x)= \begin{cases}x^{3} \ln x^{2}+x^{5}-x^{4}, & x \neq 0 \\ 0, & x=0\end{cases}
$$


Choose $x^{*}=1$. We also have that

$$
\begin{aligned}
& f^{\prime}(x)=3 x^{2} \ln x^{2}+5 x^{4}-4 x^{3}+2 x^{2}, \\
& f^{\prime \prime}(x)=6 x \ln x^{2}+20 x^{3}+12 x^{2}+10 x
\end{aligned}
$$

and

$$
f^{\prime \prime \prime}(x)=6 \ln x^{2}+60 x^{2}-24 x+22 .
$$

Notice that $f^{\prime \prime \prime}(x)$ is unbounded on $D$. Hence, the results in $[19,23]$, cannot apply to show the convergence of method (1.2) (see also the numerical examples).

The rest of the paper is organized as follows. In Section 2 we present the local convergence analysis of methods (1.2)-(1.4). The numerical examples are given in the concluding Section 3.

\section{Local convergence}

The local convergence of method (1.2), method (1.3) and method (1.4) is based on some functions and parameters. Let $K_{0}>0, K>0, L_{0}>0, L>0, M \geq 1$ and $\beta \in S$ be given parameters. Let $g_{1}, p_{1}, h_{p_{1}}, p_{2}$ and $h_{p_{2}}$ be functions defined on the interval $\left[0, \frac{1}{L_{0}}\right)$ by

$$
\begin{aligned}
g_{1}(t) & =\frac{L t}{2\left(1-L_{0} t\right)} \\
p_{1}(t) & =\frac{L_{0} t}{2}+M g_{1}(t) \\
h_{p_{1}}(t) & =p_{1}(t)-1, \\
p_{2}(t) & =L_{0} t+\frac{M^{2} t^{2}}{1-L_{0} t} \\
h_{p_{2}}(t) & =p_{2}(t)-1
\end{aligned}
$$

and parameter $r_{1}$ by

$$
r_{1}=\frac{2}{2 L_{0}+L}
$$

We have that $g_{1}\left(r_{1}\right)=1$ and for each $t \in\left[0, r_{1}\right): 0 \leq g_{1}(t)<1$. We also get that $h_{p_{1}}(0)=h_{p_{2}}(0)=-1<0$ and $h_{p_{1}}(t) \rightarrow+\infty, h_{p_{2}}(t) \rightarrow+\infty$ as $t \rightarrow{\frac{1}{L_{0}}}^{-}$. It then follows from the intermediate value theorem that functions $p_{1}$ and $p_{2}$ have zeros in the interval $\left(0, \frac{1}{L_{0}}\right)$. Denote by $r_{p_{1}}$ and $r_{p_{2}}$ the smallest such zeros of functions $h_{p_{1}}$ and $r_{p_{2}}$, respectively. Let $\bar{r}=\min \left\{r_{p_{1}}, r_{p_{2}}\right\}$. Define functions $g_{2}$ and $h_{2}$ on the interval $[0, \bar{r})$ by

$$
\begin{aligned}
g_{2}(t) & =\frac{L t}{2\left(1-L_{0} t\right)}+\frac{2 M^{2} g_{1}(t)}{\left(1-L_{0} t\right)\left(1-p_{1}(t)\right)} \\
& +\frac{|1+\beta| M g_{1}(t)}{1-L_{0} t}+\frac{M|\beta| g_{1}(t)}{1-p_{2}(t)}
\end{aligned}
$$

and $h_{2}(t)=g_{2}(t)-1$. We have that $h_{2}(0)=-1<0$ and $h_{2}(t) \rightarrow+\infty$ as $t \rightarrow \bar{r}^{-}$. Denote by $r_{2}$ the smallest zero of function $h_{2}$ in the interval $(0, \bar{r})$. Moreover, define 
functions $q$ and $h_{q}$ on the interval $[0, \bar{r})$ by $q(t)=L_{0} t+\left(K+K_{0}\right)\left(1+g_{2}(t)\right) t+2\left(K_{0}+\right.$ $K)\left(g_{1}(t)+g_{2}(t)\right) t$ and $h_{q}(t)=q(t)-1$. We get that $h_{q}(0)=-1<0$ and $h_{q}(t) \rightarrow+\infty$ as $t \rightarrow \bar{r}_{-}$. Denote by $r_{q}$ the smallest zero of function $h_{q}$ on the interval $(0, \bar{r})$. Let $\bar{r}_{0}=\min \left\{\bar{r}, r_{q}\right\}$.

Finally, define functions $g_{3}$ and $h_{3}$ on the interval $\left[0, \bar{r}_{0}\right)$ by

$$
g_{3}(t)=\left(1+\frac{M}{1-q(t)}\right) g_{2}(t)
$$

and $h_{3}(t)=g_{3}(t)-1$. We get that $h_{3}(0)=-1<0$ and $h_{3}(t) \rightarrow+\infty$ as $t \rightarrow \bar{r}_{0}^{-}$. Denote by $r_{3}$ the smallest zero of function $h_{3}$ on the interval $\left(0, \bar{r}_{0}\right)$. Define the radius of convergence $r$ by

$$
r=\min \left\{r_{i}\right\}, i=1,2,3
$$

Then, we have that

$$
0<r<r_{1}<\frac{1}{L_{0}}
$$

and for each $t \in[0, r)$

$$
\begin{gathered}
0 \leq g_{i}(t)<1, i=1,2,3 \\
0 \leq p_{j}(t)<1, j=1,2
\end{gathered}
$$

and

$$
0 \leq q(t)<1
$$

Let us denote by $U(v, \rho), \bar{U}(v, \rho)$ the open and closed balls in $S$ with center $v \in S$ and of radius $\rho>0$.

Next, we present the local convergence analysis of method (1.2) using the preceding notation.

Theorem 2.1. Let $F: D \subset S \rightarrow T$ be a differentiable function. Let also $[., ., . ; F]$ denote a divided difference of order two for function $F$ on D. Suppose that there exist $x^{*} \in D$

$$
F\left(x^{*}\right)=0, F^{\prime}\left(x^{*}\right) \neq 0
$$

and

$$
\left\|F^{\prime}\left(x^{*}\right)^{-1}\left(F^{\prime}(x)-F^{\prime}\left(x^{*}\right)\right)\right\| \leq L_{0}\left\|x-x^{*}\right\| .
$$

Moreover, suppose that there exist $L>0$ and $M \geq 1$ and $K>0$ such that for each $x, y, z \in D_{0}=D \cap U\left(x^{*}, \frac{1}{L_{0}}\right)$

$$
\begin{gathered}
\left\|F^{\prime}\left(x^{*}\right)^{-1}\left(F^{\prime}(x)-F^{\prime}(y)\right)\right\| \leq L\|x-y\|, \\
\left\|F^{\prime}\left(x^{*}\right)^{-1} F^{\prime}(x)\right\| \leq M, \\
\left\|F^{\prime}\left(x^{*}\right)^{-1}[x, x, y ; F]\right\| \leq K_{0},\left\|F^{\prime}\left(x^{*}\right)^{-1}[x, y, z ; F]\right\| \leq K
\end{gathered}
$$

and

$$
\bar{U}\left(x^{*}, r\right) \subseteq D
$$

where the radius of convergence $r$ is defined by (2.2). Then, the sequence $\left\{x_{n}\right\}$ generated for $x_{0} \in U\left(x^{*}, r\right)-\left\{x^{*}\right\}$ is well defined in $U\left(x^{*}, r\right)$, remains in $U\left(x^{*}, r\right)$ for each $n=0,1,2, \cdots$, and converges to $x^{*}$. Moreover, the following estimates hold

$$
\left\|y_{n}-x^{*}\right\| \leq g_{1}\left(\left\|x_{n}-x^{*}\right\|\right)\left\|x_{n}-x^{*}\right\| \leq\left\|x_{n}-x^{*}\right\|<r
$$




$$
\left\|z_{n}-x^{*}\right\| \leq g_{2}\left(\left\|x_{n}-x^{*}\right\|\right)\left\|x_{n}-x^{*}\right\| \leq\left\|x_{n}-x^{*}\right\|
$$

and

$$
\left\|x_{n+1}-x^{*}\right\| \leq g_{3}\left(\left\|x_{n}-x^{*}\right\|\right)\left\|x_{n}-x^{*}\right\| \leq\left\|x_{n}-x^{*}\right\|,
$$

where the " $g$ " functions are defined previously. Furthermore, for $T \in\left[r, \frac{2}{L_{0}}\right)$ the limit point $x^{*}$ is the only solution of the equation $F(x)=0$ in $D_{1}=D \cap \bar{U}\left(x^{*}, T\right)$.

Proof. We shall show that method (1.2) is well defined in $U\left(x^{*}, r\right)$ remains in $U\left(x^{*}, r\right)$ for each $n=0,1,2, \ldots$, and converges to $x^{*}$ so that estimates $(2.13)-(2.15)$ are satisfied. Using hypothesis $x_{0} \in U\left(x^{*}, r\right)-\left\{x^{*}\right\},(2.3)$ and (2.8), we have that

$$
\left\|F^{\prime}\left(x^{*}\right)^{-1}\left(F^{\prime}\left(x_{0}\right)-F^{\prime}\left(x^{*}\right)\right)\right\| \leq L_{0}\left\|x_{0}-x^{*}\right\| \leq L_{0} r<1 .
$$

It follows from (2.16) and the Banach Lemma on invertible functions $[3,7,14]$ that $F^{\prime}\left(x_{0}\right) \neq 0$ and

$$
\left\|F^{\prime}\left(x_{0}\right)^{-1} F^{\prime}\left(x^{*}\right)\right\| \leq \frac{1}{1-L_{0}\left\|x_{0}-x^{*}\right\|} .
$$

Hence, $y_{0}$ is well defined. By the first sub-step of method (1.2) for $n=0,(2.3),(2.4)$, (2.7), (2.9) and (2.17), we get in turn that

$$
\begin{aligned}
\left\|y_{0}-x^{*}\right\| \leq & \left\|x_{0}-x^{*}-F^{\prime}\left(x_{0}\right)^{-1} F^{\prime}\left(x_{0}\right)\right\| \\
\leq & \left\|F^{\prime}\left(x_{0}\right)^{-1} F^{\prime}\left(x^{*}\right)\right\| \\
& \times\left\|\int_{0}^{1} F^{\prime}\left(x^{*}\right)^{-1}\left(F^{\prime}\left(x^{*}+\theta\left(x_{0}-x^{*}\right)\right)-F^{\prime}\left(x_{0}\right)\right)\left(x_{0}-x^{*}\right) d \theta\right\| \\
\leq & \frac{L\left\|x_{0}-x^{*}\right\|^{2}}{2\left(1-L_{0}\left\|x_{0}-x^{*}\right\|\right)} \\
\leq & g_{1}\left(\left\|x_{0}-x^{*}\right\|\right)\left\|x_{0}-x^{*}\right\|<\left\|x_{0}-x^{*}\right\|<r
\end{aligned}
$$

which shows (2.13) for $n=0$ and $y_{0} \in U\left(x^{*}, r\right)$.

We can write by $(2.7)$ that

$$
F\left(y_{0}\right)=F\left(y_{0}\right)-F\left(x^{*}\right)=\int_{0}^{1} F^{\prime}\left(x^{*}+\theta\left(y_{0}-x^{*}\right)\right)\left(y_{0}-x^{*}\right) d \theta .
$$

Notice that $\left\|x^{*}+\theta\left(y_{0}-x^{*}\right)-x^{*}\right\|=\theta\left\|y_{0}-x^{*}\right\|<r$, so $x^{*}+\theta\left(y_{0}-x^{*}\right) \in U\left(x^{*}, r\right)$ for each $\theta \in[0,1]$. Then, by (2.10), (2.18) and (2.19), we get that

$$
\left\|F\left(y_{0}\right) F^{\prime}\left(x^{*}\right)^{-1}\right\| \leq M\left\|y_{0}-x^{*}\right\| \leq M g_{1}\left(\left\|x_{0}-x^{*}\right\|\right)\left\|x_{0}-x^{*}\right\| .
$$

We must show in turn that $F\left(x_{0}\right)-F\left(y_{0}\right) \neq 0$ and $F^{\prime}\left(x_{0}\right)+\frac{F^{2}\left(x_{0}\right)}{F^{\prime}\left(x_{0}\right)} \neq 0$. We have by (2.3), (2.5), (2.8) and (2.20) that

$$
\begin{aligned}
& \left\|\left(F^{\prime}\left(x^{*}\right)\left(x_{0}-x^{*}\right)\right)^{-1}\left(F(x)-F\left(x^{*}\right)-F^{\prime}\left(x^{*}\right)\left(x_{0}-x^{*}\right)-F\left(y_{0}\right)\right)\right\| \\
\leq & \left\|x_{0}-x^{*}\right\|^{-1}\left(\frac{L_{0}}{2}\left\|x_{0}-x^{*}\right\|^{2}+M\left\|y_{0}-x^{*}\right\|\right) \\
\leq & p_{1}\left(\left\|x_{0}-x^{*}\right\|\right)<p_{1}(r)<1,
\end{aligned}
$$

so

$$
\left\|\left(F\left(x_{0}\right)-F\left(y_{0}\right)\right)^{-1} F^{\prime}\left(x^{*}\right)\right\| \leq \frac{1}{\left\|x_{0}-x^{*}\right\|\left(1-p_{1}\left(\left\|x_{0}-x^{*}\right\|\right)\right.} .
$$


Similarly, by $(2.3),(2.5),(2.8)$ and $(2.20)$ (for $\left.x_{0}=y_{0}\right)$ that

$$
\begin{aligned}
& \left\|F^{\prime}\left(x^{*}\right)^{-1}\left(F^{\prime}\left(x_{0}\right)-F^{\prime}\left(x^{*}\right)+\frac{F^{2}\left(x_{0}\right)}{F^{\prime}\left(x_{0}\right)}\right)\right\| \\
\leq & L_{0}\left\|x_{0}-x^{*}\right\|+\frac{M^{2}\left\|x_{0}-x^{*}\right\|^{2}}{1-L_{0}\left\|x_{0}-x^{*}\right\|}=p_{2}\left(\left\|x_{0}-x^{*}\right\|\right) \\
< & p_{2}(r)<1,
\end{aligned}
$$

so

$$
\left\|\left(F^{\prime}\left(x_{0}\right)+\frac{F^{2}\left(x_{0}\right)}{F^{\prime}\left(x_{0}\right)}\right)^{-1} F^{\prime}\left(x^{*}\right)\right\| \leq \frac{1}{1-p_{2}\left(\left\|x_{0}-x^{*}\right\|\right)} .
$$

and $z_{0}$ is well defined. Using the second substep of method (1.2), (2.3), (2.17), (2.18), $(2.20),(2.22)$ and $(2.24)$ we obtain in turn that

$$
\begin{aligned}
z_{0}-x^{*}= & x_{0}-x^{*}-F^{\prime}\left(x_{0}\right)^{-1} F\left(x_{0}\right)+(2+\beta) F^{\prime}\left(x_{0}\right)^{-1} F\left(x_{0}\right) \\
& +(1+\beta) F^{\prime}\left(x_{0}\right)^{-1} F\left(y_{0}\right)-2 \frac{F^{2}\left(x_{0}\right)}{F^{\prime}\left(x_{0}\right)\left(F\left(x_{0}\right)-F\left(y_{0}\right)\right)} \\
& -\beta F^{\prime}\left(x_{0}\right) F\left(x_{0}\right)-\beta \frac{F\left(y_{0}\right)}{F^{\prime}\left(x_{0}\right)+\frac{F^{2}\left(x_{0}\right)}{F^{\prime}\left(x_{0}\right)}} \\
= & y_{0}-x^{*}-2\left[F^{\prime}\left(x^{*}\right)^{-1} F\left(x_{0}\right)\right]\left[F^{\prime}\left(x_{0}\right)^{-1} F^{\prime}\left(x^{*}\right)\right] \\
& \times\left[\left(F\left(x_{0}\right)-F\left(y_{0}\right)\right)^{-1} F^{\prime}\left(x^{*}\right)\right]\left[F^{\prime}\left(x^{*}\right)^{-1} F\left(y_{0}\right)\right] \\
& +(1+\beta)\left[F^{\prime}\left(x_{0}\right)^{-1} F^{\prime}\left(x^{*}\right)\right]\left[F^{\prime}\left(x^{*}\right)^{-1} F\left(y_{0}\right)\right] \\
& -\beta\left[F^{\prime}\left(x^{*}\right)^{-1} F\left(y_{0}\right)\right]\left[\left(F^{\prime}\left(x_{0}\right)+\frac{F^{2}\left(x_{0}\right)}{F^{\prime}\left(x_{0}\right)}\right)^{-1} F^{\prime}\left(x^{*}\right)\right],
\end{aligned}
$$

so

$$
\begin{aligned}
\left\|z_{0}-x^{*}\right\| \leq & \left\|y_{0}-x^{*}\right\| \\
& +\frac{2 M^{2}\left\|y_{0}-x^{*}\right\|\left\|x_{0}-x^{*}\right\|}{\left\|x_{0}-x^{*}\right\|\left(1-L_{0}\left\|x_{0}-x^{*}\right\|\right)\left(1-p_{1}\left(\left\|x_{0}-x^{*}\right\|\right)\right.} \\
& +\frac{|1+\beta| M\left\|y_{0}-x^{*}\right\|}{1-L_{0}\left\|x_{0}-x^{*}\right\|}+\frac{|\beta| M\left\|y_{0}-x^{*}\right\|}{1-p_{2}\left(\left\|x_{0}-x^{*}\right\|\right)} \\
= & g_{2}\left(\left\|x_{0}-x^{*}\right\|\right)\left\|x_{0}-x^{*}\right\| \leq\left\|x_{0}-x^{*}\right\|<r,
\end{aligned}
$$

which shows (2.14) for $n=0$ and $z_{0} \in U\left(x^{*}, r\right)$. Next, we must show that $A_{0} \neq 0$. Using (2.3), (2.6), (2.8), (2.11), (2.18) and (2.26), we get in turn that

$$
\begin{aligned}
& \left\|F^{\prime}\left(x^{*}\right)^{-1}\left(A_{0}-F^{\prime}\left(x^{*}\right)\right)\right\| \\
\leq \quad & L_{0}\left\|x_{0}-x^{*}\right\| \\
& +\left(K_{0}+K\right)\left[\left\|z_{0}-x^{*}\right\|+\left\|x_{0}-x^{*}\right\|\right]+2\left(K_{0}+K\right)\left[\left\|z_{0}-x^{*}\right\|+\left\|y_{0}-x^{*}\right\|\right] \\
\leq & L_{0}\left\|x_{0}-x^{*}\right\|+\left(K_{0}+K\right)\left(1+g_{2}\left(\left\|x_{0}-x^{*}\right\|\right)\left\|x_{0}-x^{*}\right\|\right. \\
& 2\left(K_{0}+K\right)\left(g_{1}\left(\left\|x_{0}-x^{*}\right\|\right)+g_{2}\left(\left\|x_{0}-x^{*}\right\|\right)\right)\left\|x_{0}-x^{*}\right\| \\
= & q\left(\left\|x_{0}-x^{*}\right\|\right)<q(r)<1,
\end{aligned}
$$


SO

$$
\left\|A_{0}^{-1} F^{\prime}\left(x^{*}\right)\right\| \leq \frac{1}{1-q\left(\left\|x_{0}-x^{*}\right\|\right)}
$$

and $x_{1}$ is well defined. Then, from $(2.3),(2.4),(2.18),(2.20)$ (for $\left.y_{0}=z_{0}\right),(2.27)$, and the last substep of method (1.2) for $n=0$, we have that

$$
\begin{aligned}
\left\|x_{1}-x^{*}\right\| & \leq\left\|z_{0}-x^{*}\right\|+\frac{M\left\|z_{0}-x^{*}\right\|}{1-q\left(\left\|x_{0}-x^{*}\right\|\right)} \\
& =g_{3}\left(\left\|x_{0}-x^{*}\right\|\right)\left\|x_{0}-x^{*}\right\| \leq\left\|x_{0}-x^{*}\right\|<r,
\end{aligned}
$$

which implies (2.15) holds for $n=0$ and $x_{1} \in U\left(x^{*}, r\right)$. By simply replacing $x_{0}, y_{0}, z_{0}, x_{1}$ by $x_{k}, y_{k}, z_{k}, x_{k+1}$ in the preceding estimates we arrive at $(2.13)-(2.15)$. Using the estimate $\left\|x_{k+1}-x^{*}\right\| \leq c\left\|x_{k}-x^{*}\right\|, c=g_{3}\left(\left\|x_{0}-x^{*}\right\|\right) \in[0,1)$, we deduce that $\lim _{k \rightarrow \infty} x_{k}=x^{*}$ and $x_{k+1} \in U\left(x^{*}, r\right)$. The proof of the uniqueness part is standard $[5]$.

Next, we introduce the needed functions as the corresponding ones above Theorem 2.1 but for method (1.3). Define functions $\varphi_{1}, \varphi_{2}, \varphi_{3}, h_{\varphi_{1}}, h_{\varphi_{2}}, h_{\varphi_{3}}$ on the interval $\left[0, \frac{1}{L_{0}}\right)$ by

$$
\begin{gathered}
\varphi_{1}(t)=\frac{12}{5} \frac{M g_{1}(t)}{1-\frac{L_{0}}{2} t}, h_{\varphi_{1}}(t)=\varphi_{1}(t)-1, \\
\varphi_{2}(t)=\frac{L_{0}}{2} t+2 M g_{1}(t), h_{\varphi_{2}}(t)=\varphi_{2}(t)-1, \\
\varphi_{3}(t)=\frac{L_{0}}{2} g_{1}(t) t \text { and } h_{\varphi_{3}}(t)=\varphi_{3}(t)-1 .
\end{gathered}
$$

We have that $h_{\varphi_{1}}(0)=h_{\varphi_{2}}(0)=h_{\varphi_{3}}(0)=-1<0$ and $h_{\varphi_{1}}(t) \rightarrow+\infty, h_{\varphi_{2}}(t) \rightarrow+\infty$, $h_{\varphi_{3}}(t) \rightarrow+\infty$ as $t \rightarrow{\frac{1}{L_{0}}}^{-}$. Denote by $r_{\varphi_{1}}, r_{\varphi_{2}}, r_{\varphi_{3}}$ the smallest zero of functions $h_{\varphi_{1}}, h_{\varphi_{2}}, h_{\varphi_{3}}$, respectively on the interval $\left(0, \frac{1}{L_{0}}\right)$. Moreover, define functions $g_{2}$ and $h_{2}$ on the interval $\left[0, r_{\varphi_{2}}\right)$ by

$$
g_{2}(t)=\left(1+\frac{M^{2}}{\left(1-L_{0} t\right)\left(1-\varphi_{2}(t)\right)}\right) g_{1}(t)
$$

and $h_{2}(t)=g_{2}(t)-1$. We get that $h_{2}(0)=-1<0$ and $h_{2}(t) \rightarrow+\infty$ as $t \rightarrow r_{\varphi_{2}}$. Denote by $r_{2}$ the smallest such zero. Finally, for

$$
\bar{r}=\min \left\{r_{\varphi_{1}}, r_{\varphi_{2}}, r_{\varphi_{3}}\right\}
$$

define functions $g_{3}$ and $h_{3}$ on the interval $[0, \bar{r})$ by

$$
\begin{aligned}
& g_{3}(t)=\left[1+\frac{M}{1-L_{0} t}\left(\frac{1}{2}+\frac{1+\frac{8 M g_{1}(t)}{5\left(1-\frac{L_{0}}{2} t\right)}+\frac{2}{5}\left(\frac{M g_{1}(t)}{1-\frac{L_{0}}{2} t}\right)^{2}}{1-\varphi_{1}(t)}\right)\left(\frac{1}{2}+\frac{M \bar{g}_{2}(t)}{1-\frac{L_{0}}{2} t}\right) g_{2}(t)\right], \\
& h_{3}(t)=g_{3}(t)-1
\end{aligned}
$$

and

$$
\bar{g}_{2}(t)=1+\frac{M^{2}}{\left(1-L_{0} t\right)\left(1-\varphi_{2}(t)\right)} .
$$


We have that $h_{3}(0)=-1<0$ and $h_{3}(t) \rightarrow+\infty$ as $t \rightarrow \bar{r}^{-}$. Denote by $r_{3}$ the smallest zero of function $g_{3}$ on the interval $(0, \bar{r})$. Define the radius of convergence $\rho_{1}$ by

$$
\rho_{1}=\min \left\{r_{i}\right\}, i=1,2,3 .
$$

Finally, for method (1.4), define functions $g_{1}$ and $g_{2}$ as in method (1.3) but define function $g_{3}$ and $h_{3}$ by

$g_{3}(t)=\left[1+\frac{M}{1-L_{0} t} \frac{1+\frac{2 M g_{1}(t)}{5\left(1-\frac{L_{0}}{2} t\right)}+\frac{1}{5}\left(\frac{M g_{1}(t)}{1-\frac{L_{0}}{2} t}\right)^{2}}{1-\varphi_{1}(t)}\left(1+\frac{4 M g_{1}(t)}{1-\frac{L_{0}}{2} t}\right) \frac{M \bar{g}_{2}(t)}{1-\varphi_{3}(t)}\right] g_{2}(t)$, $h_{3}(t)=g_{3}(t)-1$

and radius of convergence $\rho_{2}$ by

$$
\rho_{2}=\min \left\{r_{i}\right\}, i=1,2,3 .
$$

Next, drop the hypotheses on the divided differences and $K$ from Theorem 2.1 and exchange the " $g$ " functions and $r$ with the corresponding " $g$ " functions for method (1.3), $\rho_{1}$ and method (1.4), $\rho_{2}$. Call the resulting hypotheses $(\mathrm{C})$ and $(\mathrm{H})$, respectively. Then, we obtain the corresponding results.

Theorem 2.2. Under the $(C)$ hypotheses the conclusions of Theorem 2.1 hold for method (1.3) with $\rho_{1}$ replacing $r$.

Theorem 2.3. Under the (H) hypotheses the conclusions of Theorem 2.1 hold for method (1.4) with $\rho_{2}$ replacing $r$.

Remark 2.4. (a) The radius $r_{1}$ was obtained by Argyros in [2] as the convergence radius for Newton's method under condition (2.13)-(2.15). Notice that the convergence radius for Newton's method given independently by Rheinboldt [18] and Traub [21] is given by

$$
\rho=\frac{2}{3 L}<r_{1}
$$

As an example, let us consider the function $f(x)=e^{x}-1$. Then $x^{*}=0$.

Set $D=U(0,1)$. Then, we have that $L_{0}=e-1<l=e$, so

$$
\rho=0.24252961<r_{1}=0.3827 .
$$

Moreover, the new error bounds $[2,3,6,7]$ are:

$$
\left\|x_{n+1}-x^{*}\right\| \leq \frac{L}{1-L_{0}\left\|x_{n}-x^{*}\right\|}\left\|x_{n}-x^{*}\right\|^{2},
$$

whereas the old ones $[14,16]$

$$
\left\|x_{n+1}-x^{*}\right\| \leq \frac{L}{1-L\left\|x_{n}-x^{*}\right\|}\left\|x_{n}-x^{*}\right\|^{2} .
$$

Clearly, the new error bounds are more precise, if $L_{0}<L$. Clearly, we do not expect the radius of convergence of method (1.2) given by $r$ to be larger than $r_{1}$ (see (2.4)) . 
(b) The local results can be used for projection methods such as Arnoldi's method, the generalized minimum residual method(GMREM), the generalized conjugate method(GCM) for combined Newton/finite projection methods and in connection to the mesh independence principle in order to develop the cheapest and most efficient mesh refinement strategy $[2,3,6,7]$.

(c) The results can be also be used to solve equations where the operator $F^{\prime}$ satisfies the autonomous differential equation $[3,7,14,16]$ :

$$
F^{\prime}(x)=p(F(x)),
$$

where $p$ is a known continuous operator. Since $F^{\prime}\left(x^{*}\right)=p\left(F\left(x^{*}\right)\right)=p(0)$, we can apply the results without actually knowing the solution $x^{*}$. Let as an example $F(x)=e^{x}-1$. Then, we can choose $p(x)=x+1$ and $x^{*}=0$.

(d) It is worth noticing that method (1.2) are not changing if we use the new instead of the old conditions [23]. Moreover, for the error bounds in practice we can use the computational order of convergence (COC)

$$
\xi=\frac{\ln \frac{\left\|x_{n+2}-x_{n+1}\right\|}{\left\|x_{n+1}-x_{n}\right\|}}{\ln \frac{\left\|x_{n+1}-x_{n}\right\|}{\left\|x_{n}-x_{n-1}\right\|}}, \quad \text { for each } n=1,2, \ldots
$$

or the approximate computational order of convergence (ACOC)

$$
\xi^{*}=\frac{\ln \frac{\left\|x_{n+2}-x^{*}\right\|}{\left\|x_{n+1}-x^{*}\right\|}}{\ln \frac{\left\|x_{n+1}-x^{*}\right\|}{\left\|x_{n}-x^{*}\right\|}}, \quad \text { for each } n=0,1,2, \ldots
$$

instead of the error bounds obtained in Theorem 2.1. Related work on convergence orders can be found in [8].

(e) In view of (2.9) and the estimate

$$
\begin{aligned}
\left\|F^{\prime}\left(x^{*}\right)^{-1} F^{\prime}(x)\right\| & =\left\|F^{\prime}\left(x^{*}\right)^{-1}\left(F^{\prime}(x)-F^{\prime}\left(x^{*}\right)\right)+I\right\| \\
& \leq 1+\left\|F^{\prime}\left(x^{*}\right)^{-1}\left(F^{\prime}(x)-F^{\prime}\left(x^{*}\right)\right)\right\| \leq 1+L_{0}\left\|x-x^{*}\right\|
\end{aligned}
$$

condition (2.11) can be dropped and $M$ can be replaced by

$$
M(t)=1+L_{0} t
$$

or

$$
M(t)=M=2,
$$

since $t \in\left[0, \frac{1}{L_{0}}\right)$.

\section{Numerical Example}

We present a numerical example in this section.

Example 3.1. Returning back to the motivation example at the introduction on this paper, we have $L_{0}=L=96.662907, M=1.0631, K=K_{0}=\frac{L}{2}, \beta=-1$. Then, the parameters for method (1.2) are

$$
r_{1}=0.0069, r_{2}=0.0051=r, r_{3}=0.1217 \text {. }
$$

We have $A C O C=1.7960$ and $C O C=1.8371$. 


\section{References}

[1] Argyros, I.K., Quadratic equations and applications to Chandrasekhar's and related equations, Bull. Aust. Math. Soc., 32(1985), 275-292.

[2] Argyros, I.K., A unifying local-semilocal convergence analysis and applications for twopoint Newton-like methods in Banach space, J. Math. Anal. Appl., 298(2004), 374-397.

[3] Argyros, I.K., Computational theory of iterative methods, Series: Studies in Computational Mathematics, 15, Editors: C.K. Chui and L. Wuytack, Elsevier Publ. Co. New York, U.S.A, 2007.

[4] Argyros, I.K., Chen, D., Results on the Chebyshev method in Banach spaces, Proyecciones, 12(2)(1993), 119-128.

[5] Argyros, I.K., George, S., Alberto Magrenan, A., Local convergence for multi-pointparametric Chebyshev-Halley-type methods of high convergence order, J. Comput. Appl. Math., 282(2015), 215-224.

[6] Argyros, I.K., Hilout, S., Weaker conditions for the convergence of Newton's method, J. Complexity, 28(2012), 364-387.

[7] Argyros, I.K., Hilout, S., Numerical Methods in Nonlinear Analysis, World Scientific Publ. Comp. New Jersey, 2013.

[8] Cătinaş, E., A survey on the convergence radius and computational orders of sequences, Appl. Math. Comput., 343(2019), 1-20.

[9] Chun, C., Stanica, P., Neta, B., Third order family of methods in Banach spaces, Comput. Math. Appl., 61(2011), 1665-1675.

[10] Gutiérrez, J.M., Hernández, M.A., Recurrence relations for the super-Halley method, Comput. Math. Appl., 36(1998), 1-8.

[11] Hernández, M.A., Salanova, M.A., Modification of the Kantorovich assumptions for semilocal convergence of the Chebyshev method, J. Comput. Appl. Math., 126(2000), 131-143.

[12] Hernández, M.A., Chebyshev's approximation algorithms and applications, Comput. Math. Appl., 41(2001),433-455.

[13] Hernández, M.A., Second derivative free variant of the Chebyshev method for nonlinear equations, J. Optim. Theory. Appl., 104(2000), no. 3, 501-515.

[14] Hueso, J.L., Martinez, E., Tervel, C., Convergence, efficiency and dynamics of new fourth and sixth order families of iterative methods for nonlinear systems, J. Comput. Appl. Math., 275(2015), 412-420.

[15] Kantorovich, L.V., Akilov, G.P., Functional Analysis, Pergamon Press, Oxford, 1982.

[16] Magreñán, Á.A. , Estudio de la dinámica del método de Newton amortiguado (PhD Thesis), Servicio de Publicaciones, Universidad de La Rioja, 2013.

[17] Petkovic, M.S., Neta, B., Petkovic, L., Džunič, J., Multipoint Methods for Solving Nonlinear Equations, Elsevier, 2013.

[18] Rheinboldt, W.C., An adaptive continuation process for solving systems of nonlinear equations, In: Mathematical Models and Numerical Methods (A.N. Tikhonov et al. eds.), pub. 3, (19), 129-142 Banach Center, Warsaw Poland.

[19] Siyyam, H.I., Taib, M., Alsubaihi, I.A., A new one parameter family of iterative methods with eight-order of convergence for solving nonlinear equations, Int. J. Pure and Appl. Math., 84(2013), no. 4, 451-461. 
[20] Sharma, J.R., Some fifth and sixth order iterative methods for solving nonlinear equations, Ranji Sharma Int. Journal of Engineering Research and Applications, 4(2014), no. 2, 268-273.

[21] Traub, J.F., Iterative methods for the solution of equations, Prentice Hall Series in Automatic Computation, Englewood Cliffs, N.J., 1964.

[22] Wang, X., Kou, J., Semilocal convergence and R-order for modified Chebyshev-Halley methods, Numer. Algorithms, 64(2013), no. 1, 105-126.

[23] Wang, X., Liu, L., New eight-order iterative methods for solving nonlinear equations, J. Comput. Appl. Math., 234(2010), 1611-1620.

Ioannis K. Argyros

Department of Mathematical Sciences

Cameron University, Lawton, OK 73505, USA

e-mail: iargyros@cameron.edu

Santhosh George

Department of Mathematical and Computational Sciences

National Institute of Technology Karnataka

575025 India

e-mail: sgeorge@nitk.edu.in 